\title{
Uso, residualidad y problemática del siglo VIII en el palacio de época visigoda del Tolmo de Minateda (Hellín, Albacete)
}

\author{
Usage, remanence and VIII century issues in the visigothic palace at Tolmo \\ de Minateda (Hellín, Albacete)
}

Víctor Cañavate Castejón *

José Antonio Mellado Rivera *

Julia Sarabia Bautista *

\begin{abstract}
RESUMEN
En el presente trabajo se exponen los principales contextos cerámicos emanados del estudio estratigráfico en el palacio de época visigoda. A partir de la secuencia estratigráfica ha sido posible determinar que, como se venía observando en otras construcciones de origen visigodo, en el palacio existe una voluntad de reempleo y modificación espacial que se verá truncado con la construcción del barrio de época emiral a finales del siglo VIII o principios del siglo IX. Los materiales documentados en estos niveles corresponden al Horizonte II -entre mediados y finales del siglo VIII-, horquilla temporal que permite corroborar los resultados obtenidos en anteriores estudios, y que demuestra una pervivencia de formas cerámicas de tradición visigoda medio siglo después de la conquista.
\end{abstract}

Palabras clave: Tolmo de Minateda, basilica, palacio, habitación, horizonte, contexto, siglo VIII, secuencia estratigráfica, cerámica visigoda, cerámica islámica, expolio de materiales de construcción.

El Tolmo de Minateda (Fig. I) es un asentamiento que ofrece una evidente continuidad en el poblamiento altomedieval, característica que proporciona una evolución tipológica del material cerámico cimentada en la estratigrafía. Esta coyuntura permite situar la mayoría de las producciones cerámicas en su contexto cronológico adecuado. Los últimos estudios

\begin{abstract}
In the present work the main ceramic contexts emanated from the stratigraphic study in the visigothic palace are exposed. From the stratigraphic sequence it has been possible to determine that, as observed in other constructions of visigothic origin, in the palace exists an aim of reuse and space modification that will be truncated with the construction of the district of emiral time at the end of 8th century or the beginnings of 9th century. The materials documented in these levels correspond to Horizon II -between mid and final of 8th century-, a chronological interval that corroborates the results obtained in previous studies, and demonstrates a continuity of visigothic tradition pottery forms half century after the conquest.
\end{abstract}

Key Words: Tolmo de Minateda, basilica, palace, room, horizon, context, 8th century, stratigraphic sequence, Visigothic pottery, Islamic pottery, plundering of building materials.

realizados sobre la cerámica del yacimiento (GUTIÉRREZ, GAMO y AMORÓs: 2003) han permitido establecer con fiabilidad una secuenciación cronológica basada en tres horizontes, de los que el I -la producción cerámica visigoda del s. VII- y el III -la producción islámica del s. IX- parecen bastante delimitados en cuanto a tipología.

\footnotetext{
* Departamento de Prehistoria, $\mathrm{H}^{\mathrm{a}}$. Antigua y Arqueología; Universidad de Alicante. Este trabajo se ha realizado dentro del proyecto HUM - 2006 - 09874/Hist. Un proceso de romanización comparada: los casos de llici y Elo. Proyecto de investigación y desarrollo científico del Ministerio de Educación y Ciencia.
} 
No ocurre igual con el horizonte intermedio, el II, al que pertenece la producción del s. VIII. Este período de transición desde la cultura material plenamente visigoda a la cultura material de época emiral, ha dejado de ser un "cajón de sastre" ceramológico en lo que al Tolmo se refiere gracias al estudio antes mencionado, $y$ a otros de recientes pendientes de publicación'. El análisis de las estancias de la basilica ha permitido saber que es un horizonte en el que predominan las formas visigodas -las botellas, los cuencos carenados, las ollas T6.2, los jarros TI 8 y TI 9 (GUTIÉRREZ, 1996)-, o al menos se trata de una cerámica de tradición visigoda, mientras que asociada a ésta comienzan a aparecer las primeras formas islámicas (ollas de borde bífido típicas del Tolmo y las jarras pintadas TI I.I) muy probablemente a finales del siglo VIII.

Si se atendiera exclusivamente al análisis de la cerámica sería complicado fechar algunos contextos pues perfectamente podrían ser del VII o del VIII debido a la evidente continuidad de las formas, de manera que los niveles del s. VIII se convertirían en "niveles evanescentes" y se podría diferenciar entre uso y residualidad.

Pero en el Tolmo se dispone de una estratigrafía sólida y fiable, y es en el propio análisis estratigráfico donde se debe iniciar la tarea de individualizar las formas típicas del siglo VIII. La metodología de trabajo en el campo ha permitido determinar los diferentes momentos postdeposicionales -bajo la denominación de niveles de uso, abandono y destrucción-, y con esta base se puede abordar con profundidad el estudio preliminar de los materiales de esos niveles para poder establecer el grado de uso o residualidad de las formas visigodas en el siglo VIII.

\section{El Horizonte II en la basílica}

El registro estratigráfico vinculado a este horizonte ha sido definido en varias publicaciones a partir de la aparición de los primeros usos domésticos en diversos puntos de la basilica. Esta transformación ilustra la desacralización del edificio reforzada por una serie de repavimentaciones con estratos arcillosos naranjas que se extienden en las diferentes estancias reocupadas. Los repertorios cerámicos documentados sobre estos suelos son necesariamente posteriores al abandono de la iglesia como edificio de culto. Los contextos analizados son todos anteriores a la remodelación urbanística plenamente emiral, que se sitúa entre un momento muy avanzado del siglo VIII y con toda probabilidad en los inicios del siglo IX. En este sentido, la segunda mitad del siglo VIII sería el intervalo temporal entre el abandono litúrgico de la iglesia y la recuperación sistemática de materiales para las nuevas construcciones ${ }^{2}$.

Las conclusiones extraídas sobre el Horizonte II en la basilica son de gran relevancia, al tiempo que deben ligar con los contextos estratigráficos adscritos al mismo, sean o no contemporáneos. No se debe olvidar que el registro material responde estratigráficamente a una horquilla limitada entre la reutilización de diferentes dependencias de la basilica tras el cese de las actividades litúrgicas -sin que se pueda aseverar con rotundidad que tal reempleo de los espacios fuera sincrónico-, y el arranque del complejo urbano emiral. En este sentido, hay que señalar que en los ajuares cerámicos de esta fase predominan las producciones de facies visigoda y características del Horizonte I: a torno destacan botellas TI5.5, ollas con borde vuelto y con encaje para tapadera T6.2 marmitas M2.1.2; jarros con o sin boca trilobulada de excelente calidad -series TI8 o TI9- y cazuelas a torno. A mano

\footnotetext{
I Nos referimos al estudio del repertorio ceramológico realizado por Victoria Amorós, que responde a su memoria de licenciatura inédita ("Contextos cerámicos del siglo VIII en el Tolmo de Minateda"), donde se realiza una extensa exposición de los repertorios formales documentados en la basílica en este horizonte.

2 Es necesario manifestar que el abandono de la actividad litúrgica se realiza bien entrado el siglo VIII y no a consecuencia de la conquista; la desacralización y consiguiente conversión del edificio de culto se realizarán de forma dilatada a partir del ecuador del siglo VIII.
} 
predominan las ollas con asa de lengüeta $y$ tapaderas planas M30.I.I (GUTIÉRREZ, GAMO y AMORÓs, 2003: 148).

En todos estos contextos analizados aparecieron formas nuevas que se han convertido en verdaderos indicadores cronológicos: las ollas de borde bífido o moldurado tm/Tol.4 y tm / Tol. 3 ; l las cazuelas de fondo convexo con asas, aunque con escasa representación (GUTIÉRREZ, GAMO y AMORÓS, 2003: I 48; AMORÓS, inédito); tazas de finas paredes de dos o más asas y cuencos carenados (Fig. 2).

Uno de los elementos significativos será la aparición de los jarritos de boca ancha TII y T20, sobre todo en los paquetes asociados a los grandes expolios de la basilica. Son formas de pastas amarillentas con decoración pintada en óxido de hierro, que durante estos contextos conviven con las formas tradicionales visigodas, y que perduran durante la centuria siguiente, lo que refuerza la datación postvisigoda de dichos contextos. Del mismo modo sucede con los candiles, asociados al cambio a formas más esféricas del cuerpo de las botellas en los albores del siglo IX (AMORÓs, inédito).

\section{El palacio de época visigoda}

El inicio del estudio de los contextos materiales debe partir del análisis descriptivo del edificio que configura, junto a la basilica, uno de los edificios más importantes del complejo principal de la ciudad en época visigoda. Constituye una edificación entorno a un espacio abierto, con orientación EsteOeste y paralela a la iglesia y delimitada por una zona cementerial ad sanctos (Este) y una zona porticada (Oeste), que permite el ingreso a una plaza flanqueada al sur por la basíica ${ }^{4}$ (Fig. 3). Su planta es compleja, con diferentes habitaciones comunicadas entre sí y espacios a priori abiertos que se distribuyen a partir de un eje Este-Oeste que crea dos fábricas (GUTIÉRREZ y CÁNOVAS, 2009: 95). Al oeste, junto al pórtico, se encuentra el vestíbulo ${ }^{5}$, con planta rectangular y orientación Norte-Sur, que da acceso a un espacio abierto por el norte, $y$ a oriente permite el acceso a dos estancias consecutivas y alineadas ${ }^{6}$ que dirigen al espacio de mayor representatividad del edificio. La primera -habitación 176- admite además el ingreso por el sur a una pequeña dependencia 7 que conserva los restos de una probable caja de escalera, lo que indicaría el acceso a un segundo piso o zona elevada. La segunda -habitación 175- interviene a modo de sala de espera del aula ${ }^{8}$, dependencia de mayor prestigio del edificio, de planta rectangular y perpendicular al eje principal, con machones interiores. Esta sala aparece separada en dos naves a partir de una columnata central de la que se conservan los entalles de las basas (GUTIÉRREZ y CÁNOVAS, 2009: 96).

\footnotetext{
3 Este tipo de olla, inexistente en el Horizonte I, se incrementa en número conforme avanza el siglo VIII. Su vacío durante los contextos del siglo VII ha planteado la innovación del tipo, sobre todo en cuanto a la forma del borde, ya que el cuerpo es similar al de las T.6, y habitualmente sin asas (AMORÓs: inédito).

4 Para un análisis más detallado de la basilica ver: ABAD CASAL, L. y GUTIÉRREZ LLORET, S., 1997: "Iyih (EI Tolmo de Minateda, Hellín, Albacete). Una ciuitas en el limes visigodo-bizantino", Antigüedad y Cristianismo (Murcia), XIV (I997), 59I-600; ABAD CASAL, L., GUTIÉRREZ LLORET, S. y GAMO PARRAS, B., 2000 a: "La ciudad visigoda del Tolmo de Minateda (Hellín, Albacete) y la sede episcopal de Eio", Los orígenes del cristianismo en Valencia y su entorno (Grandes temas arqueológicos II), Valencia, IOI-I2.; ABAD CASAL, L.; GUTIÉRREZ LLORET, S. y GAMO PARRAS, B., 2000 B: "La basilica y el baptisterio del Tolmo de Minateda (Hellín, Albacete)", Archivo Español de Arqueología, 73, 193-221; GUTIÉRREZ LLORET, S.; ABAD CASAL, L. y GAMO PARRAS, B., 2004: “La iglesia visigoda de El Tolmo de Minateda (Hellín, Albacete)", Sacralidad y Arqueología. Thilo Ulbert zum 65 Geburtstag am Juni 2004 gewidmet (J. M. ${ }^{a}$ Blázquez y A. González Blanco, eds.) apud Antigüedad y Cristianismo (Murcia), XXI, I37-70; GUTIÉRREZ LLORET, S.; ABAD CASAL, L. y GAMO PARRAS, B., 2005: "Eio, lyyuh y el Tolmo de Minateda (Hellín, Albacete): de sede episcopal a madîna islámica", Les ciutats tardoantigues d'Hispania: cristianització i topografia, Institut d'Estudis Catalans VI Reunió d'Arqueología Cristiana Hispànica (Valencia, 2003), Barcelona, 345-68; GUTIÉRREZ, S. y CÁNOVAS, P.: "Construyendo el siglo VII: arquitecturas y sistemas constructivos en el Tolmo de Minateda", Anejos de AespA, LI, 9 | - | 32.

5 Habitación 178.

6 Habitaciones 176 y 175 respectivamente.

7 Habitación 177.

8 Habitación 182.
} 
Finalmente, sin conexión directa con los espacios descritos, restan tres dependencias, una ${ }^{9}$ situada a oriente y en paralelo al aula, que conserva dos machones en la cara internas de su cierre oriental; $y$ otras dos ubicadas al sur del eje principal del edificio, que abren al pasillo que comunica la zona porticada con la plaza interior $^{\prime 0}$. La primera de estas dos dependencias ${ }^{\prime \prime}$ está flanqueada por el norte con la habitación 177, y al oeste con el pórtico y el vestíbulo, y se caracteriza junto con la segunda 12 por mantener entradas independientes del resto.

\section{Análisis de los contextos cerámi- cos del s. VIII en el palacio.}

Hasta los últimos años, la certeza en la datación del Horizonte II emanaba del análisis de la secuencia estratigráfica en la basilica, ya que la datación de estos contextos por su contenido artefactual llevaría, en rigor, a situar las producciones de aspecto visigodo en el siglo VII y las islámicas en el IX sin problemas, quedando el siglo VIII vacío.

Tras las intervenciones llevadas a cabo en el edificio ubicado al norte de la basílica, e interpretado como palacio episcopal de una nueva sede creada a finales del siglo VI ${ }^{13}$, surge el análisis de la secuencia estratigráfica en las diferentes estancias, constatándose la existencia de un proceso evolutivo que viene enmarcado en dos momentos bien distintos. En el primero existe una voluntad de aprovechamiento inicial de las estancias del palacio, modificando su morfología exclusivamente para las nuevas necesidades; $y$ un segundo momento en donde se produce una rápida transformación espacial, quizás condicionada a las nuevas necesidades arquitectónicas y al quizás cada vez mayor arraigo cultural islámico.
El primer momento de ocupación tiene una ubicación estratigráfica entre el complejo de época visigoda y las viviendas de época islámica incuestionable. Las cerámicas aparecidas en los niveles de destrucción de las dependencias así como en los restos de las pavimentaciones, lo demuestran. Pese a que no se han documentado importantes ajuares que denoten un marcado carácter doméstico, existen algunas formas de clara tradición visigoda que se mezclan con otras que indican el inicio de unos nuevos tipos de producción, como es caso de las ollas de borde bífido tm/Tol.4 y tm /Tol.3.

En rigor, este momento aparece reflejado por una serie de estratos bien definidos; los más modernos, compuestos por derrumbes o abandonos con abundante material, superpuestos a un estrato arcilloso y compacto de color naranja sobre la roca, con escaso material cerámico, que se extiende en gran parte de las estancias del edificio. Los dos niveles parecen constituir los momentos de uso y abandono de las estancias del palacio con posterioridad a su uso original. La naturaleza de los paquetes naranjas parece reflejar la voluntad de crear una repavimentación en aquellas estancias del palacio que tienden a reemplearse en este momento.

Posteriormente, en un momento inmediatamente anterior a que el solar se modifique considerablemente en época emiral, se asiste a la ruina total de la gran mayoría de las estancias que con anterioridad conformaron el palacio, cuando se produce un importante truncamiento que, en dirección este-oeste, altera en gran medida la prolongación de sus cierres occidentales y orientales (GUTIÉRREZ y CÁNOVAS, 2009: 103, fig. 6). Esta acción negativa se realizó para el expolio de parte de los muros de las estancias visigodas situadas al norte. De la misma forma,

\footnotetext{
9 Habitación 174.

10 Espacio 181.

I) Habitación 179.

12 Habitación 180.

13 Por su disposición y dependencia, parece más que probable que el edificio tuviera una función de representación, administración y residencia, semejante a algunas residencias episcopales conocidas en Barcelona (GUTIÉRREZ y CÁNOVAS, 2009: I26).
} 
en gran parte de los espacios se documenta la continua explotación de sus recursos materiales reflejado en diferentes zanjas de expolio que, en mayor o menor medida, convierten el edificio en una cantera de extracción. De esta forma, las estancias 176 y 177 se ven afectadas por un potente truncamiento que altera algunos de sus cierres, así como la estratigrafía depositada sobre la propia roca (Fig. 4).

La analogía contextual que se desprende tras el análisis estratigráfico con la basílica parece bastante convincente. En ambos casos se definen dos momentos de uso bien delimitados. En el primero ya se observa una clara desvinculación con la funcionalidad original de la edificación; existe una voluntad de construir un nuevo suelo asociado a una serie de cambios en la morfología original del edificio, que se vincula a la aparición de un nuevo elenco cerámico en los depósitos que lo amortizan más relacionado al mundo doméstico. En el segundo, la disolución con la función prístina de ambas edificaciones es prácticamente pareja, si bien es cierto que en la basílica los efectos de las actividades de expolio parece que afectaron únicamente a los espacios de grandes dimensiones y a aquellas zonas que albergaron los elementos rituales, en el palacio los despojos de material y truncamientos se diversificaron en zonas aisladas a excepción de la mutilación de los cierres laterales del aula y de parte de las estancias 182, 175, 176 y 178.

En este sentido, conviene analizar detalladamente los contextos cerámicos de aquellas habitaciones del palacio reutilizadas para conocer las características del segundo horizonte. Se trata de siete espacios bien definidos, relacionados de forma diferente con la transformación del palacio en un ámbito ajeno a su concepción prístina. Parte de estas habitaciones -los espacios 174, 179, 180 y 181- se mantienen inconexas, mientras que el resto - 175, 176 y 177 - quedan comunicados por los vanos originales del edificio. Por otro lado, la mayor parte de las habitaciones conforman el E.H. I I ${ }^{14}$, excepto I79, I 80 y 181 , que se engloban en el E.H. $12{ }^{15}$.

En cualquier caso todos los espacios son reempleados una vez que el palacio ha perdido su función original, ya que se trata precisamente de la transformación de las habitaciones del palacio en ambientes domésticos, o al menos en espacios con una carga funcional sensiblemente diferente. La permanencia de estos reempleos es difícil de atestiguar con seguridad; la estratigrafía marca el fin a partir de la creación del barrio de época emiral que se superpone a los restos del palacio, sin que existan unas fechas claras para tal solución. La aparición de un felús de primera época ${ }^{16}$ en una de las repavimentaciones del palacio -habitación 176- permite, por un lado, ubicar cronológicamente la fundación del barrio en un momento impreciso entre finales del siglo VIII e inicios del IX, y por otro, corroborar que los repertorios cerámicos procedentes de los niveles de abandono y destrucción situados entre dichos suelos y los niveles de construcción del citado barrio responden a un momento impreciso de la segunda mitad del siglo VIII (DOMÉNECH y GUTIÉRREZ, 2006: 356; GUTIÉRREZ y CÁNOVAS, 2009: 102-13).

\section{I. La habitación I74}

Este espacio de planta rectangular y orientación norte-sur es, en su génesis, uno de los más difíciles de interpretar dentro de palacio. La existencia de una estructura frontera escalonada, e interpretada como uno de los accesos al

\footnotetext{
I4 La denominación E.H. (espacio habitacional) ha sido adoptada por el equipo de investigación como herramienta de trabajo para designar cada uno de los complejos conformados por diversas estructuras arquitectónicas -tanto aisladas como yuxtapuestas o contiguas- que pueden identificarse como unidades domésticas amplias en un sentido funcional.

I 5 La situación de ambos espacios habitacionales - I I y 12-respeta en gran medida la disposición original de cada una de las estancias en el momento en que se construyó el palacio. La existencia de diferentes construcciones o usos indica que el palacio se "parcela" siguiendo el eje este-oeste original que separa las habitaciones septentrionales de las meridionales.

16 Se trata de un cobre tosco de elevado peso que recuerda a los feluses norteafricanos de primera época (DOMÉNECH y GUTIÉRREZ, 2006: 372)
} 
edificio (GUTIÉRREZ y CÁNOVAS, 2009: 124), admite una comunicación descubierta, al menos parcialmente, a este espacio que sí debió estar techado, explicando la presencia de los dos pilares de sustentación o contrafuertes interiores en su extremo oriental ${ }^{17}$. Posteriormente, tras el abandono primigenio del palacio en la estancia se suceden una serie de paquetes de abandono y destrucción que alternan con acciones de expolio que reconfiguran la planta original del espacio. El potente truncamiento que afecta a las habitaciones septentrionales del palacio, modificando la planta original del edificio, rompe el trazado de los muros oriental y septentrional de 174 hasta la roca, así como a todos los depósitos estratigráficos previos. La habitación sufre una reorganización con la construcción de un paramento ${ }^{18}$, en cuya composición encontramos un parteluz de ventana geminada o ajimez que indudablemente perteneció a uno de los edificios del complejo visigodo (GUTIÉRREZ y SARABIA, 2006: fig. 16.4; SARABIA, 2009: fig. 2). Por fin, la estancia quedó obliterada por parte del barrio emiral, sirviendo los muros del palacio como cimentación a las nuevas estructuras ex nouo (GUTIÉRREZ y CAÑAVATE, e.p.).

Sobre los contextos cerámicos extraídos en la secuencia estratigráfica (Fig. 5), y empezando por el estrato más antiguo -el nivel de abandono directamente sobre la roca ${ }^{19}$-, se observa una serie de hallazgos cerámicos significativos: cuencos -uno de ellos un tm/Tc.2 (Fig. 5.7)-, una botella de un asa -posibleTI5.5 (Fig. 5.8)-, varias ollas, una de ellas T6.2 (Fig. 5.3), una tapadera tm/Tk (Fig. 5.9) (GUTIÉRREZ y CÁNOVAS, 2009: 125) y cazuelas. Es un conjunto variado de tradición visigoda, que podría adscribirse al Horizonte I sin problemas si se atiende exclusivamente a las formas. Superpuesto aparece otro nivel de abandono 20 que presenta un cuenco a mano de producción local tm/Mc.3 (Fig. 5.6), varias ollas -entre las que destacan dos T6.2 (Fig. 5.4 y 5.5)-, y una marmita M2.I (Fig. 5.I), predominante en contextos del siglo VII y primera mitad del VIII (GUTIÉRREZ, 1996: fig. 77, I). Hay que subrayar la presencia de un borde de marmita que recuerda más a las M4 islámicas que a las M2.2 visigodas del Horizonte II (Fig. 5.2), aunque podría tratarse de una inusual -al menos en el Tolmo- MI.3, fechada por S. Gutiérrez en la segunda mitad del siglo VII o principios del VIII y por tanto ser una producción visigoda (GUTIÉRREZ, 1996: fig. 74, I y 2). Este tipo de pieza aparecerá en otras habitaciones del palacio, en los niveles que obliteran los suelos naranjas. Finalmente, se observa un potente derrumbe ${ }^{21}$ sobre el que se documenta el truncamiento que afecta a las diferentes estancias del palacio, así como el paramento ex nouo con el parteluz reempleado. Este paquete se encuentra en contacto con los derrumbes de colmatación y abandono islámicos superpuestos, de ahí que presente formas islámicas que, como sucede en la basilica, sólo aparecen como muy temprano a finales del siglo VIII, generalizándose durante el siglo IX: un borde de jarro pintado (T20.3) y un borde de marmita islámica M4.I.

Los dos últimos estratos analizados constituyen el nivel de abandono del segundo momento de uso de la habitación; pero mientras el material cerámico documentado en el primero es de facies visigoda, en el segundo, no obstante, encontramos ya piezas típicas de contextos emirales.

Por tanto, los niveles más antiguos presentes en la habitación presentan un contexto cerámico genuinamente visigodo, con predominio

\footnotetext{
17 Se ha planteado la posibilidad de que la estancia nunca fuera usada o incluso que nunca fuera terminada de construir. Esto explicaría el hecho de que el suelo aquí sea demasiado irregular. En cualquier caso parece claro que durante la reestructuración acometida en el periodo de ocupación que aquí tratamos, la habitación fue utilizada íntegramente, ya que si bien es la única estancia que carece de repavimentación, tampoco existen acciones negativas -realizadas en este momento- que intuyan un expolio de material.

18 U.E. 61787.

19 U.E. 62477.

20 U.E. 62465 .

21 U.E. 62055 .
} 
de las piezas de la segunda mitad del siglo VII, y con una continuidad tipológica en la primera mitad del siglo VIII sin apenas cambios, lo que podría conllevar la ocupación de la habitación a posteriori a su uso original, al menos hasta mediados del siglo VIII. A tenor de la complejidad estratigráfica de la estancia, notablemente afectada con posterioridad, parece que 174 fue expoliado por completo en el momento de la reocupación de las diferentes estancias del edificio visigodo.

\subsection{La habitación $\mathbf{I 7 5}$}

Se trata del espacio ubicado entre el aula, al este, y la habitación 176, al oeste. Con esta último conforma las dos cámaras axiales del ala septentrional, con un marcado carácter de tránsito, patente en el alineamiento de sus vanos (GUTIÉRREZ y CÁNOVAS, 2009: 125), que permite el acceso desde el vestíbulo hasta el aula. Hasta su completa amortización en época emiral plena, la habitación conserva su planta cuadrangular original, siendo la tercera estancia más reducida de todo el palacio con dieciséis $\mathrm{m}^{2}$. Asimismo, conserva en su pared meridional los asientos tallados para encajar las semicolumnas adosadas (GUTIÉRREZ y CÁNOVAS, 2009: 96), enfrentadas a un vano tapiado de antiguo que probablemente permitiría el acceso a un espacio de difícil interpretación ${ }^{22}$.

En cuanto a la estratigrafía documentada en su interior (Fig. 6), el nivel más antiguo está constituido por un aporte antrópico que se extiende sobre la propia roca ${ }^{23}$, un suelo naranja de composición arcillosa correspondiente a un uso posterior del espacio palatino, y contemporáneo a la existencia de dos umbrales realzados a cota del mismo en los vanos de acceso al aula y a 176 El material más significativo documentado es un borde de ánfora romana Keay $L X I$, un borde de cuenco visigodo (Fig. 6.1) y dos bordes de olla (Fig. 6.2 y 6.3 ).

El material más interesante aparece en los paquetes que amortizan el pavimento naranja ${ }^{24}$, puesto que junto a un fragmento de vidriado visigodo, la pieza más significativa del conjunto la constituye una marmita de borde reentrante y base convexa que presenta una morfología a caballo entre las M2 visigodas y las M4 islámicas (Fig. 6.4), y que por tanto constituye un tipo relativamente nuevo que hasta ahora no había aparecido en su contexto en el yacimiento. Planteamos la hipótesis de que pueda tratarse de un tipo evolucionado de las M2 adscrito al Horizonte II, que sin embargo no perdura más allá de este horizonte, ya que aparecen por el contrario las marmitas M4 de base plana y borde reentrante.

Por encima del pavimento naranja pero infrapuesto a los niveles pertenecientes al segundo momento de uso se observan dos estratos de derrumbe ${ }^{25}$, ambos con material poco significativo de tradición visigoda y sin que se constaten pastas islámicas.

\subsection{La habitación 176}

Es la habitación contigua y alineada por el oeste a 175, y por lo tanto abierta hacia la misma por medio de un vano en paralelo con el eje este-oeste del palacio. Se trata de una estancia con una planta de tendencia rectangular, aunque algo más compleja, que encuentra dividida por un murete lateral que separa la parte de la habitación que permite el acceso a 177.

La estratigrafía de esta habitación se encuentra truncada desde el comienzo de la excavación por una zanja de expolio que llega hasta la roca madre en algunas zonas, una enorme acción

22 Únicamente se ha conservado un muro exento que probablemente cerraría la hipotética habitación por el norte.

23 U.E. 62484.

24 U.E. 62368.

25 UU.EE. 62367 y 62366. 
negativa que afecta a prácticamente la totalidad de la mitad sur del espacio ${ }^{26}$. Con todo, en la zona de esta habitación donde la estratigrafía no se encontraba dañada por la zanja, interesa destacar la deposición ininterrumpida de diferentes paquetes estratigráficos que condicionan el espacio. De esta forma se suceden depósitos y paquetes de diferente naturaleza que amortizan el uso primigenio de 176 (Fig. 6). En primer lugar la degradación original de la habitación, que supone la formación del primer paquete de abandono ${ }^{27}$, con escaso material significativo. Posteriormente, un pavimento de similares características a los documentados en la iglesia o en la habitación $175^{28}$, relacionado con el realzado de los umbrales que dan acceso a 175 por el este y al vestíbulo 178 por el oeste, y en consecuencia con una subida en la cota del nivel de paso. Este uso se ve amortizado por una serie de paquetes de derrumbe 29 que responden al deterioro de los alzados de esta parte del edificio; una degradación que se verá acelerada por la aparición de las primeras zanjas de expolio ${ }^{30}$ para el aprovechamiento de material constructivo en un segundo uso constatado en el espacio ${ }^{31}$. Los paquetes ${ }^{32}$ que obliteran este segundo uso, responden a la deposición de abandonos y arrastres previos a la construcción del barrio.

El material cerámico documentado en la repavimentación del primero de los dos usos es bastante escaso en cuanto a formas, aunque lo más destacable es la aparición del felús nortearfricano de primera época (DOMÉNECH y GUTIÉRREZ, 2006: 356; GUTIÉRREZ y CÁNOVAS, 2009: 102-13), datado en el ecuador del siglo VIII ${ }^{33}$. Esta moneda está, por estratigrafía, en un nivel posterior al uso original del palacio pero claramente anterior a los niveles que contienen cerámica islámica. De hecho, en los estratos superpuestos al pavimento no se ha constatado material islámico, lo que llevaría la datación del citado pavimento hasta bien entrado el siglo VIII.

Si la repavimentación presentaba material poco significativo, no ha sido ese caso en los estratos superpuestos, tanto en los paquetes que amortizan directamente la repavimentación como los que obliteran el segundo nivel de uso en el espacio. Se ha documentado un conjunto bastante homogéneo de tradición visigoda, aunque caracterizado por piezas incompletas: un fragmento de vidriado visigodo, un fragmento cuenco visigodo, un borde de olla T6.2 y otro de cazuela sin que se hayan constatado pastas islámicas amarillentas, lo que confirma que las producciones cerámicas del Horizonte II son claramente de tradición visigoda, y que sólo a finales del siglo VIII comienzan a aparecer formas locales propiamente islámicas en su factura.

\subsection{La habitación 177}

Este contexto se localiza en el interior de la habitación situada al sur de la anterior, con la que tiene acceso. Se trata de un espacio ciego de pequeño tamaño -tan solo $9 \mathrm{~m}^{2}$ - paralelo al vestíbulo que debió tener un segundo piso, a juzgar por los bloques de opus signinum caídos del suelo superior y el probable arranque de una escalera que aún se conserva; podría tratarse de un acceso puntual a las cubiertas del inmueble, ya que en el resto de lugares no hay evidencia manifiesta de una segunda planta, o

\footnotetext{
26 Más que una zanja de expolio, parece tratarse de una excavación "arqueológica" que, tal vez realizada a finales del siglo XIX o inicios del $X X$, había seguido como referencia el muro meridional, que podía ser visto en superficie, probablemente reempleado dentro del entramado urbanístico emiral.

27 U.E. 62490.

28 U.E. 62475.

29 UU.EE. 62470, 62062 y 62380.

30 U.E. 62120 y la ya citada U.E. 62296.

31 Este uso engloba las UU.EE. 62061, 61830 y 62119

32 UU.EE. 62060, 61997,61774 y 61796.

$33 \mathrm{Vid} . \mathrm{n} 16$
} 
bien el inicio de una zona elevada con carácter de torre o campanario, (GUTIÉRREZ y CÁNOVAS, 2009: 96 y 125) que aclararía quizá los contrafuertes que refuerzan la pared occidental de esa estancia desde el vestíbulo. Como ocurre con el resto de las estancias reempleadas del edificio, parece que una vez que ésta abandona su uso primigenio se transforma en una dependencia más del nuevo entramado habitacional, aunque inseparable de 176, si se tiene en cuenta la correlación entre los depósitos estratigráficos de ambas habitaciones. En cualquier caso, parece que únicamente se reutiliza la mitad norte de la habitación, puesto que el característico pavimento naranja aparece en la mitad septentrional, aunque puede darse el caso de que la parte sur se haya perdido, debido seguramente al proceso de desmonte que sufre el edificio en los usos posteriores.

El contexto material de esta habitación se vincula a la propia transformación de la habitación palatina, y por tanto al primer momento de uso. Tras la deposición del primer abandono ${ }^{34}$ se documentó la repavimentación naranja 35 que tiene continuidad con la habitación 176 a través del vano de acceso. Superpuesto al suelo naranja y a la caja de escalera se documenta un paquete de derrumbe ${ }^{36}$ que, como el suelo, traspasa los límites de la habitación. Este derrumbe aparece cubierto por unos paquetes que contenían abundantes placas de opus signinum ${ }^{37}$ muy basto y de considerable espesor que estaba afectado por una zanja de robo que se internaba también en $176^{38}$, lo que revela que tras el desplome de los alzados de 177 existió una voluntad de expoliar material de construcción en este sector del palacio. Por fin, se depositan estratos que cubren los desplomes y las acciones de robo que se extienden desde la habitación 176, sobre los que construyen las estructuras de las estancias correspondientes a la fase más antigua del barrio emiral.
El material que aparece previo a la reutilización del espacio es escaso, donde destaca parte de una jarra tm/Tjr.l y un borde de botella visigoda. En el pavimento naranja el material es prácticamente inexistente pero en el paquete de derrumbe posterior se recupera un repertorio material que parece constituir el ajuar doméstico de una vivienda, en el que destacan varios fragmentos de vedríos visigodos, una marmita M2.I típica (Fig. 6.5), parte de una cazuela y diversos fragmentos de una botella; todos son materiales de tradición visigoda, y se pueden adscribir a los Horizontes I y || sin problemas. El derrumbe con bloques de opus signinum no contiene material reseñable pero destaca por un borde de pasta amarillenta islámica.

El derrumbe superpuesto, que determina el segundo momento de frecuentación en el espacio, contiene un fragmento de olla de borde bífido tm/Tol.3.; mientras que los paquetes que determinan el abandono y derrumbe final del palacio tras el segundo momento de uso no contienen materiales reseñables, si bien empiezan a aparecer pastas amarillentas.

\subsection{La habitación 179}

Como la habitación 177 se trata de una de las más reducidas, ocupa tan solo unos $11 \mathrm{~m}^{2}$ y tiene una planta rectangular con orientación norte-sur. Esta habitación, tiene el vano orientado al sur, por lo que su acceso está totalmente segregado del resto, y se realiza desde el pasillo que da paso desde la zona porticada al espacio abierto |8|.

Una vez se interrumpe su uso original, la habitación se encuentra en un proceso de transformación similar a otras documentadas en el edificio (Fig. 7). Sobre la roca se obra un suelo ${ }^{39}$ arcilloso naranja que constituye el

\author{
34 U.E. 62494. \\ 35 U.E. 62493 \\ 36 U.E. 62384. \\ 37 UU.EE. 62191 y 61998 \\ 38 La anteriormente citada U.E. 62120. \\ 39 U.E. 62466.
}


nivel de uso de la primera fase de reocupación. Tras la regularización se asiste a un proceso de degradación marcada por una serie de derrumbes ${ }^{40}$ que marcan el deterioro de la habitación hasta el preparado ${ }^{41}$ previo de la superficie de toda la zona para el asentamiento de diferentes estructuras asociadas al barrio emiral.

El contexto material documentado es significativo por la aparición en el pavimento y en el primer derrumbe que lo amortiza de dos ollas de pasta castaña-rojiza, con aspecto visigodo pero que constituyen una producción inusual (Fig. 7.I y 7.2). Ambas tienen el cuerpo ovoide, con el borde ligeramente exvasado de labio curvo, acanaladuras en el cuerpo y sin asas. En cuanto al borde es similar a las ollas T6.2, mientras que el cuerpo se asemeja más a las T6. I, forma que empieza a aparecer en estos contextos; no obstante debe de tratarse de un tipo nuevo hasta ahora desconocido en el repertorio material. Junto a estas nuevas formas se recogen algunos fragmentos de vidriado visigodo y parte de una botella TI5.5.

En los derrumbes superiores existe un rico elenco material caracterizado por fragmentos de ollas, marmitas, botellas y cazuelas sin especificar, así como un fragmento de melado verde propio del Horizonte III; sin embargo, a pesar de la presencia de este vedrío el contexto no presenta pastas islámicas amarillentas; además no se constatan jarros ni jarras pintadas.

Como viene siendo frecuente en el momento de reocupación, atestiguada en el reempleo de las dependencias situadas al norte, oeste y noreste de 179, no existen restos de estruc- turas que permitan definir una funcionalidad concreta para la habitación. El material aparecido en los niveles de destrucción de la estancia parece asociarse a un espacio claramente doméstico; el contexto cerámico es visigodo y los primeros materiales islámicos -el vidriado melado-verde-, se encuentra en el derrumbe infrapuesto al nivel claramente emiral.

\subsection{La habitación 180}

Pese a tratarse de una de las habitaciones más grandes -aproximadamente $33 \mathrm{~m}^{2}$-, en origen no parece que formara parte de la estructura funcional del edificio; junto con la habitación 179 tiene la disposición de su vano abierto al pasillo próximo entre el pórtico y el espacio |8|. Esta orientación del vano implica, de una lado, independencia con respecto a los espacios de mayor representatividad, y de otro, que la funcionalidad pudo estar alejada del ámbito simbólico, quizá con una mayor carga administrativa o privada (GUTIÉRREZ y CÁNOVAS, 2009: 125).

El contexto estudiado procede de los paquetes que amortizan el uso primigenio de la habitación hasta su completa ruina con la erección del barrio (Fig. 7). La fase más antigua está constituida por los restos de una pavimentación arcillosa, similar a la documentada en otras estancias palatinas ${ }^{42}$, que marca por tanto un momento de uso y reempleo de la habitación ${ }^{43}$. Superpuestos a los restos del pavimento aparecen paquetes de derrumbe ${ }^{44}$ como producto del inicio de la desolación de I80, obliterados, a su vez por un nivel de abandono ${ }^{45}$ sobre cuya superficie se encuentra un

\footnotetext{
40 UU.EE. 62381, 62105 y 62071.

4 I U.E. 61883.

42 UU.EE. 62512,62513 y 62514

43 Como se viene atestiguando para este momento en la gran mayoría de habitaciones del antiguo edificio, existen indicios de reutilización a partir de una repavimentación que, en este caso, ha llegado de una manera lamentable. Únicamente se conservaban tres manchas no muy extensas que se extienden por la mitad meridional de la estancia. Su precario estado de conservación podría deberse en gran medida al temprano desmoronamiento de los alzados así como de las acciones de expolio realizadas en la fase de uso posterior.

44 UU.EE. 62478 y 62467.

45 U.E. 62387.
} 
hogar asentado ${ }^{46}$ de factura simple, estructura que marca un segundo uso de la habitación. El abandono de este uso viene representado por un único estrato que aparece obliterado por dos derrumbes ${ }^{47}$. Finalmente, surge el nivel ${ }^{48}$ sobre el que levantan las estructuras asociadas al entramado emiral, que contenía numerosos fragmentos de enlucidos de cal caídos que en alguna de sus caras presentaba incisiones, representando líneas, dibujos zoomorfos y abundantes letras en cursiva visigoda.

Entre los materiales documentados en los derrumbes situados entre los dos usos hay que destacar una campaniense como elemento residual, vidriado visigodo (GUTIÉRREZ, GAMO y AMORÓs 2003: 134), una botella visigoda de boca trilobulada con un asa (Fig. 7.7), ollas T6.2 (Fig. 7.3 y 7.4), varias marmitas, una de ellas con base convexa y borde reentrante (Fig. 7.6), y otra M2. I, dos cuencos visigodos, uno de ellos tm/ Tc.2, un jarro con pico vertedor T26 y varios fragmentos de una tinaja. En los estratos que obliteran el segundo uso hay poco material significativo, aunque empiezan a aparecer formas y pastas islámicas: un vidriado melado-verde, una olla de borde bífido tm/Mol.4 y algunas marmitas, entre las que destaca el borde una posible M4 (Fig. 7.5).

\subsection{El espacio $|8|$}

Se trata de un espacio de grandes dimensiones que se encuentra en el sector que más alteraciones sufrió desde su abandono de época visigoda hasta la reurbanización emiral. Buena parte de la estratigrafía interior así como su posible cierre meridional se han perdido por las continuas acciones de expolio así como por el objetivo de alojar una serie de viviendas pertenecientes al entramado emiral, por lo que por el momento la información es bastante incompleta. Estos hechos determinan que la interpretación prístina del espacio resulte especialmente compleja. Existen restos de muros que flanquean el espacio por el sur y este, "...que pudieron corresponder tanto a estructuras previas arrasadas como a porches y estructuras..." (GUTIÉRREZ y CÁNOVAS, 2009: 124 y 15). En cualquier caso parece que este espacio debió constituir una especie de patio o de zona descubierta acotada por el este y norte, cuyo ingreso debía realizarse necesariamente desde la zona porticada del complejo episcopal y quizá desde la entrada monumental a la basilica.

Tras el desmonte las estructuras de época emiral asociadas al barrio, se podía ver en toda la zona central del espacio la roca madre recortada a modo de plataforma al mismo nivel horizontal sobre el que se construye la basilica de época visigoda, y a una cota superior a la del resto del palacio. Bajo los niveles constructivos emirales se conservaban, además de la roca, dos áreas con estratigrafía fiable (Fig. 8). En la primera de ellas superpuesto a los rellenos de la zanja de cimentación del muro meridional del aula, aparecen las primeras señales de abandono ${ }^{49}$, sobre las que se documentan unos materiales que marcan un nivel de frecuentación posterior al uso original del edificio. Sobrepuesto a este uso aparece un derrumbe ${ }^{50}$ sobre el que se construye una tinajera ${ }^{51}$ compuesta por cuatro lajas dispuestas de forma vertical (CAÑAVATE, 2008: 242 y 272, lam. 14. I), que denota claramente una funcionalidad doméstica 0 industrial del espacio en estos contextos. Este segundo uso aparece cubierto por un paquete de abandono ${ }^{52}$ sobre el que se depositan ya los estratos que sirven de cimentación a las estructuras del barrio.

46 U.E. 62464.

47 UU.EE. 62188 y 61930.

48 U.E. 61883.

49 U.E. 62495.

50 U.E. 62019 .

5 I U.E. 6128I.

52 U.E. 62018 
En la segunda zona -junto al aula y las habitaciones 175 y 180 - tras el abandono del palacio ${ }^{53}$, empiezan a acumularse estratos que marcan una frecuentación asociada probablemente a los materiales documentados en la primera zona del espacio ${ }^{54}$. Este uso se amortiza con diferentes paquetes de abandono y derrumbe ${ }^{55}$ que tienen como fin una segunda frecuentación marcada por el levantamiento de lo que parece ser una estructura singular en cuya construcción se reemplearon varias ventanas monolíticas con los extremos fragmentados y dispuestas de forma lineal con el intradós hacia abajo (GUTIÉRREZ y SARABIA, 2006: figs. 15. I-2, 4, 8- I 0, y SARABIA, 2009: I33- I 34, fig. 3) ${ }^{56}$. Tal momento de uso aparece obliterado por aportes y abandonos ${ }^{57}$ sobre los que se construyen las diversas estructuras asociadas al entramado urbano emiral.

Entre los contextos materiales procedentes del espacio I8I, sobresale la presencia de un rico elenco cerámico caracterizado por formas de cocina procedente de los paquetes que amortizan el primer nivel de frecuentación, en el que apuntan diferentes marmitas, entre las que destacan dos ejemplos de base convexa (Fig. 8.I y 8.2), un cuenco carenado ${ }^{58}$ (Fig. 8.4), y varios fragmentos asociados a ollas T6.2.

De otra parte, las pastas amarillentas, típicamente emirales, no empiezan a aparecer -aunque escasas y poco reseñables- hasta los paquetes que amortizan el segundo momento de uso, siendo éstas prácticamente inexistentes entre los estratos que marcan las frecuentaciones del espacio durante este periodo. En los paquetes que sellan este contexto hay que señalar un borde de olla a mano M6.I (Fig. 8.3), el tercio superior de una jarra con restos de pintura castaña que conserva el arranque de dos de sus asas (Fig. 8.5), un cuenco (Fig. 8.7) y parte de una olla con restos de engobe anaranjado en el interior y exterior de la pieza (Fig. 8.6).

\section{Observaciones generales sobre el Horizonte II en el palacio}

El estudio pormenorizado de los contextos cerámicos, obtenido gracias al análisis de la secuencia estratigráfica, se corresponde con la reutilización de los diferentes espacios del palacio con un fin probablemente doméstico en un periodo previo a la construcción del barrio emiral. Esta afirmación lleva en conclusión a presentar unos rasgos generales sobre la tipología cerámica característica y sobre cómo aparece representado el Horizonte II en el edificio palatino.

Del análisis del material cerámico de los suelos o pavimentaciones ${ }^{59}$ de las habitaciones estudiadas se extrae, primero, que el material es escaso en general, pero muestra algunas formas enteras muy interesantes y novedosas, donde es evidente el aspecto claramente visigodo que exhibe. Se constatan fragmentos muy pequeños de vidriado visigodo (pertenecientes a ollas V6.2) pero claramente residuales en este momento, junto a botellas TI 5.5 (Fig. 5.8), marmitas M2.I (Fig. 5.I y 6.5) y cuencos visigodos (Fig. 5.6, 5.7, 6. I , 8.4 y 8.7), que sí son habituales.

\section{U.E. 62319.}

54 UU.EE. 62314,62315 y 62316 .

55 UU.EE. 62025, 62279, 6227I, 62272, 62273, 62274, 62275, 62276, 62277, 62284, 62292, 62223, 62238, 62222, 62224 y 61880.

56 U.E. 61755 . La colocación de estos elementos, hizo suponer en un principio una funcionalidad de pileta o pesebre; no obstante, al estar situada en paralelo con el cierre septentrional que cerraba el espacio en origen, podría pensarse en otra función bien distinta, quizá como tabique delimitador de una estancia ex nouo.

57 UU.EE. 62158, 62148, 61879 y 61597.

58 Los fragmentos de esta pieza aparecieron dispersos entre diferentes paquetes postdeposicionales del espacio I8I y del aula, acción que por otro lado justifica que después del abandono original del palacio y tras el primer momento de ocupación del mismo existe una voluntad de expolio y de remoción de escombros que desfigura el edificio visigodo.

59 Las UU.EE. 62368, 62475, 62493 y 62466 de las habitaciones 175, 176, 177 y 179 respectivamente, y las UU.EE. 62512, 62513 y 62514 de la habitación 180. 
A estas formas se añaden otras que aparecen en aquellos niveles equivalentes a estos suelos ${ }^{60}$, que se usan como niveles de frecuentación, a saber, las ollas T6.2 (Fig. 5.3, 5.4, 5.5, 7.3 y 7.4), un borde de ánfora spatheion y alguna orza tm/ Torz.3. A este contexto de tradición visigoda, que tiene continuidad en el siglo VIII -como se atestigua en los mismos contextos de la basílica-, se asocian dos nuevos tipos: una olla de pasta visigoda de cuerpo ovoide -que aparece sobre el suelo de la habitación 179 y sobre el estrato superpuesto (Fig. 7.I y 7.2)-, y las marmitas de borde reentrante y base convexa, de las que se han atestiguado varios ejemplares tanto en los niveles de frecuentación como en los niveles superpuestos (Fig. 5.2, 6.4, 7.6, 8. I y 8.2). En este sentido, se puede afirmar que existe una evolución autóctona dentro de lo visigodo, quizá unos tipos visigodos tardíos más que ante una primera aportación islámica.

Además de estas novedades tipológicas, la gran mayoría de los paquetes estratigráficos adolecen de pastas claras islámicas o formas asociadas a la fase urbanística emiral, excepto un fragmento de olla de borde bífido tipo tm/Tol.4, habitual en los contextos emirales del Tolmo (Horizonte III), pero que está atestiguado en este horizonte en la basilica (AMORÓs: inédito), y que puede aparecer ya en el último cuarto del siglo VIII. Esta primera presencia material islámica resulta normal, pero llama más la atención la presencia del felús emiral en la superficie del suelo de la habitación 176, y por tanto contemporáneo al conjunto de tradición visigoda con el que se relaciona. La existencia de esta moneda prueba que se trata de contextos del siglo VIII, y por tanto del Horizonte II. Con todo, el siglo VIII presenta una evidente continuidad tipológica de las formas visigodas que ya había sido constatada en la basilica y que ahora en el palacio queda corroborada.

Igual de interesante resulta el análisis tipológico extraído a partir de los derrumbes que cubren el primero momento de frecuentación en el palacio, que deben relacionarse con los expolios masivos para la extracción de materiales de construcción expolio de sus materiales. Es en este momento cuando se erigen los paramentos que contienen los elementos reempleados -el tabique con el parteluz y el muro de ajimeces-, probablemente extraídos de los alzados del complejo visigodo, contribuyendo a la transformación del espacio y a la deformación de la planta edilicia previa. Formalmente, en el primer nivel de derrumbes no existen evidencias notables con el momento de uso de las estancias del palacio; se siguen repitiendo las formas de tradición visigoda -ollas T6.2, marmitas MI.3 y M2.1, cuencos visigodos y un jarro con pico vertedor T26. Asimismo continúan ausentes las pastas amarillentas islámicas -con la única salvedad de un borde de jarro pintado T20.3 de finales del siglo VIII, auque es más común en el siglo IX-, y se constata una marmita de base convexa que ya había aparecido en los niveles infrapuestos. En el segundo nivel de derrumbes la presencia de las primeras formas islámicas de finales del siglo VIII es ya evidente; las ollas de borde bífido, ya sean a mano o a torno, el jarro pintado T20.3, la marmita M4.I -formas que se generalizan en el siglo IX-, y junto a estas nuevas formas, todavía escasas, se siguen asociando las formas tradicionales visigodas, es decir, ollas T6.2 o algún que otro cuenco, relacionado con marmitas de base convexa típicas de esta centuria. Este tipo de marmitas, al igual que el cuenco carenado ${ }^{61}$, se encuentran en usos claramente posteriores al original del palacio, e ilustran una fase avanzada de su abandono.

La impresión que dan estos paquetes de derrumbes pertenecientes al segundo nivel es que la tradición visigoda continúa siendo predominante pese a que ahora se asocian a nuevas formas islámicas cuya presencia es todavía muy escasa. Sólo en los derrumbes inmediatamente anteriores a los estratos que sirven de cimiento

60 La U.E. 62477 de la habitación 174

6 I Estos cuencos carenados de tradición visigoda son frecuentes en los contextos del s. VIII, aunque en los contextos del palacio únicamente se cuente con un ejemplo, por lo que puede parecer que su testimonio es residual. 
para la reurbanización emiral son habituales las ollas de borde bífido -las marmitas M4. I, la olla T6. I y el vidriado islámico-, aunque no se puede hablar en ningún momento de ruptura material, ya que en estos últimos niveles siguen apareciendo, ya de forma más residual, las formas visigodas características del siglo VII.

Finalmente, se asiste a una evolución tipológica donde el predominio de lo visigodo se mantiene perfectamente hasta finales del siglo VIII y sólo en el cambio de centuria parece comenzar el predominio de lo islámico, como ya se venía advirtiendo en los contextos estudiados en la basílica. Este curso, entre el abandono del palacio y la construcción del barrio emiral, depende en gran medida de la seriación estratigráfica, de tal forma que su ausencia inclinaría las formas típicas visigodas al Horizonte I y las islámicas al Horizonte III. En este sentido, el palacio aporta una variedad de formas visigodas que abarca el ajuar típico de ambientes domésticos (ollas, marmitas, jarros, cazuelas y cuencos), asociado, como hemos podido comprobar, a un felús emiral del siglo VIII que permite contextualizar los conjuntos cerámicos analizados. Por fin, las formas visigodas del siglo VII no solo no son residuales en el siglo VIII, sino que permanecen en uso hasta bien entrado el siglo, lo cual significa que a la hora de analizar futuros contextos cerámicos visigodos habrá que tener muy en cuenta cuál es la proporción de formas islámicas presentes.

\section{BIBLIOGRAFÍA}

ABAD CASAL, L. y GUTIÉRREZ LLORET, S. ( 1997): 'lyih (El Tolmo de Minateda, Hellín, Albacete). Una ciuitas en el limes visigodo-bizantino", Antigüedad y Cristianismo. XIV, 59|-600.

ABAD CASAL, L., GUTIÉRREZ LLORET, S. y GAMO PARRAS, B. (2000a): "La ciudad visigoda del Tolmo de Minateda (Hellín, Albacete) y la sede episcopal de Eio", Los orígenes del cristianismo en Valencia y su entorno (Grandes temas arqueológicos II). I0 I- |2. Valencia.

ABAD CASAL, L.; GUTIÉRREZ LLORET, S. y GAMO PARRAS, B. (2000b): "La basílica y el baptisterio del Tolmo de Minateda (Hellín, Albacete)", Archivo Español de Arqueología. 73, 193-221.
ALBA CALZADO, M. (2003): "Apuntes sobre la cerámica de épocas tardoantigua (visigoda) y altomedieval (emiral) en Extremadura a partir del registro arqueológico emeritense", Anejos del AespA. XXVIII, 293-332.

ALBA, M. y FEIJOO, S. (200 I): "Cerámica emiral de Mérida", Garb. Sitios islámicos del Sur de Portugal. 329-376.

ALBA CALZADO, M. y GUTIÉRREZ LLORET, S. (2008): "Las producciones de transición al mundo islámico: el problema de la cerámica paleoandalusí (siglos VIII y IX)", Cerámicas hispanorromanas. Un estado de la cuestión. XXVI Congreso Internacional de la asociación Rei Cretariae Romanae. 585-6I3. Cádiz.

AMORÓS RUIZV. (inédito): Contextos cerámicos del sig/o VIII en el Tolmo de Minateda.

CABALLERO ZOREDA, L.; RETUERCE VELASCO, M. y SÁEZ LARA, F. (2003): "Las cerámicas del primer momento de Santa María de Melque (Toledo), construcción, uso y destrucción", Anejos de AespA XXVIII. 225-27I.

CAÑAVATE CASTEJÓN,V., 2008: Estructuras domésticas de época altomedieval en el sureste peninsular: El Tolmo de Minateda (Hellín, Albacete), Instituto de Estudios Albacetenses, Albacete.

CAÑAVATE CASTEJÓN, V., GUTIÉRREZ LLORET, S., MELLADO RIVERA, J. A. y SARABIA BAUTISTA, J. (inédito): “Para qué la cerámica?: implicaciones metodológicas del estudio contextual de la cerámica emiral. El Tolmo de Minateda", La cerámica altomedieval de la Península Ibérica (siglos VII-X). Hacia una propuesta común (Jornadas de estudio sobre la cerámica de la cerámica de la Alta Edad Media II). Casa de Velázquez-l'École française de Rome. Marzo 2007. Madrid.

DOMÉNECH BELDA, C. y GUTIÉRREZ LLORET, S. (2005): "Las monedas de El Tolmo de Minateda, Hellín (Albacete)", XIII Congreso Internacional de Numismática, |567-|576. Madrid.

DOMÉNECH BELDA, C. y GUTIÉRREZ LLORET, S. (2006): "Viejas y nuevas monedas en la ciudad emiral de Madinat lyyuh (El Tolmo de Minateda, Hellín, Albacete)", Al-Qantara. XXVII, 2, julio-diciembre. 337-374.

GODOY FERNÁNDEZ, C. (1995): Arqueología y liturgia. Iglesias hispánicas (siglos IV al VIII). Universitat de Barcelona.

GUTIÉRREZ LLORET, S. (1988): Cerámica común paleoandalusí del sur de Alicante (siglos VIII-X). Alicante.

GUTIÉRREZ LLORET, S. (1996): La Cora de Tudmir: de la antigüedad tardía al mundo islámico, (CCV 57). MadridAlicante.

GUTIÉRREZ LLORET, S. (1999): "la cerámica emiral de Madinat lyyuh (el Tolmo de Minateda, Hellín, Albacete). Una primera aproximación", Arqueología y territorio medieval. 6. Jaén, 7|-|| I.

GUTIÉRREZ LLORET, S. (2000ª): "El espacio doméstico altomedieval del Tolmo de Minateda (Hellín, Albacete), entre el ámbito urbano y rural", Castrum 6, Maisons et espaces domestiques dans le monde Méditerranéen aun Moyen Âge, CEFR 105/6-CCV. 72. Rome-Madrid, I5I-64. 
GUTIÉRREZ LLORET, S. (2000b): "Algunas consideraciones sobre la cultura material de las épocas visigoda y emiral en el territorio de Tudmir", Visigodos y Omeyas. Un debate entre la Antigüedad Tardía y la Alta Edad Media (Mérida, 1999), Anejos de AEspA XXIII. 95-I I 6.

GUTIÉRREZ LLORET, S. (2002): "De espacio religioso a espacio profano: transformación del área urbana de la basilica del Tolmo de Minateda (Hellín, Albacete) en barrio islámico", II Congreso de Historia de Albacete (Albacete, noviembre del 2000).

GUTIÉRREZ LLORET, S.; GAMO PARRAS, B. y AMORÓS RUIZ,V. (2003): "Los contextos cerámicos altomedievales del Tolmo de Minateda y la cerámica altomedieval en el sudeste de la Península Ibérica", Cerámicas tardorromanas y altomedievales en la península Ibérica. Ruptura y continuidad, Anejos de AespA. XXVIII, I 19-168.

GUTIÉRREZ LLORET, S.; ABAD CASAL, L. y GAMO PARRAS, B. (2004): "La iglesia visigoda de El Tolmo de Minateda (Hellín, Albacete)", Sacralidad y Arqueología. Thilo Ulbert zum 65 Geburtstag am Juni 2004 gewidmet (J. M. ${ }^{a}$ Blázquez y A. González Blanco, eds.) apud. Antigüedad y Cristianismo. XXI. Murcia, I37-70.

GUTIÉRREZ LLORET, S.; ABAD CASAL, L. y GAMO PARRAS, B. (2005): "Eio, lyyuh y el Tolmo de Minateda (Hellín, Albacete): de sede episcopal a madîna islámica", Les ciutats tardoantigues d'Hispania: cristianització i topografia, Institut d'Estudis Catalans. VI Reunió d'Arqueología Cristiana Hispànica (Valencia, 2003). Barcelona, 345-68.
GUTIÉRREZ LLORET, S. (2007): "La islamización de Tudmir: balance y perspectivas", Villa II. Villes et campagnes de Tarraconaise et d'al-Andalus (Vlé - Xlé siècles): la Transition; Ph. Sénac, (Ed.)/Etudés Medievales Iberiques. 275-318.

GUTIÉRREZ LLORET, S. y CÁNOVAS GUILLÉN, P. (2009): "Construyendo el siglo VIl: arquitecturas y sistemas constructivos en el Tolmo de Minateda", Anejos de AespA. LI. 91- 132.

GUTIÉRREZ LLORET, S. y CAÑAVATE CASTEJÓN, V. (e.p.): "Casas y cosas: espacios y funcionalidad en las viviendas emirales del Tolmo de Minateda (Hellín, Albacete)", Cuadernos de Madinat al-Zahrā'. Córdoba.

MALPICA CUELLO, A. y CARVAJAL LÓPEZ, J.C. (Eds.) (2007): Estudios de cerámica tardorromana y altomedieval. Granada.

SARABIA BAUTISTA, I. (2003): Los elementos arquitectónicos ornamentales en el Tolmo de Minateda (Hellín, Instituto de Estudios Albacetenses, Albacete.

SARABIA BAUTISTA, J. (2009): "El aprovisionamiento de materia prima para la construcción de ambientes domésticos de época emiral", Lucentum. XXVII. I31-139.

VIGIL-ESCALERA GUIRADO, A. (2003): "Cerámicas tardorromanas y altomedievales de Madrid", Cerámicas tardorromanas y altomedievales en la península Ibérica. Ruptura y continuidad, Anejos de AespA. XXVIII. 37I-387. 

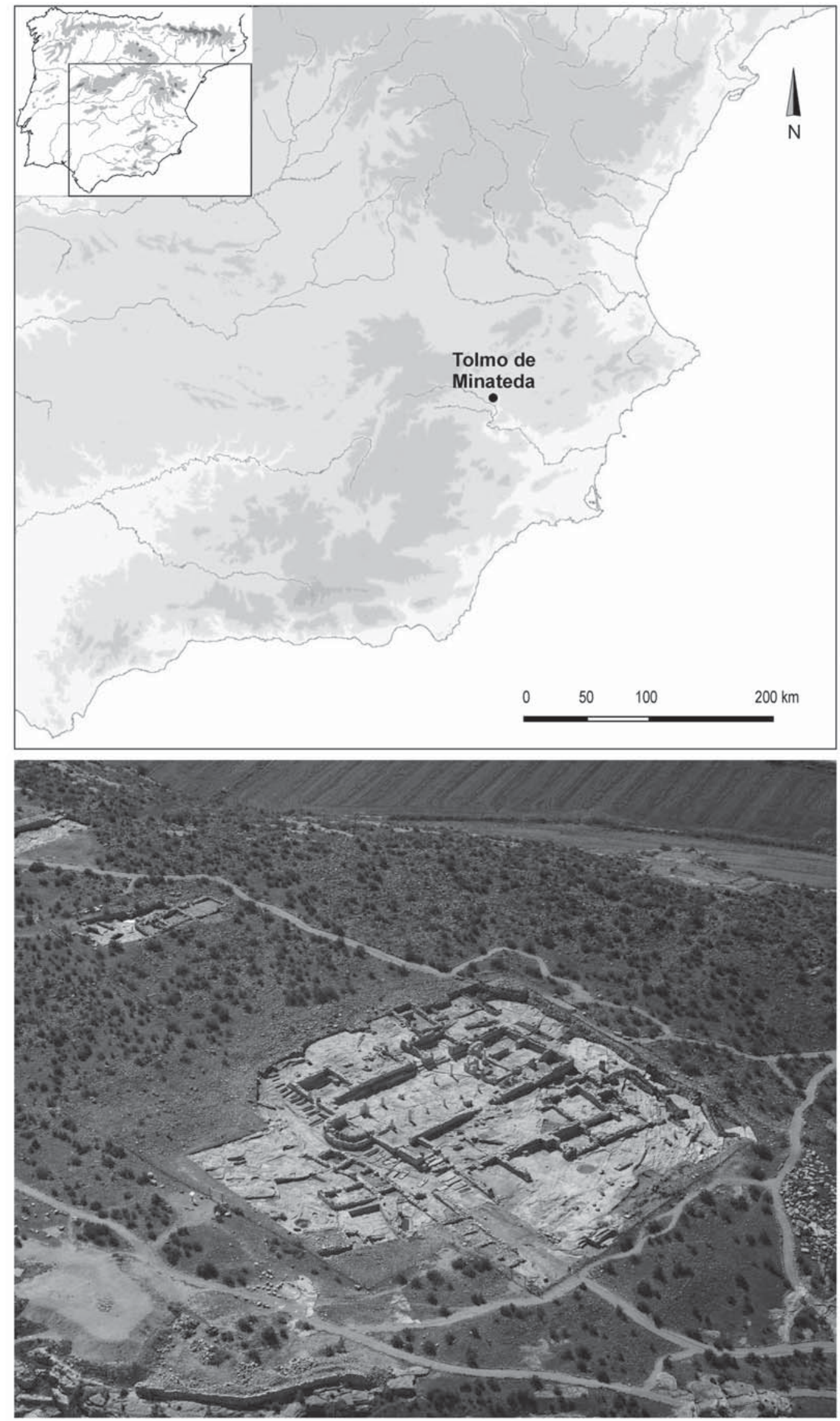

Figura I. Ubicación del yacimiento arqueológico del Tolmo de Minateda. Delimitación del área estudiada. 


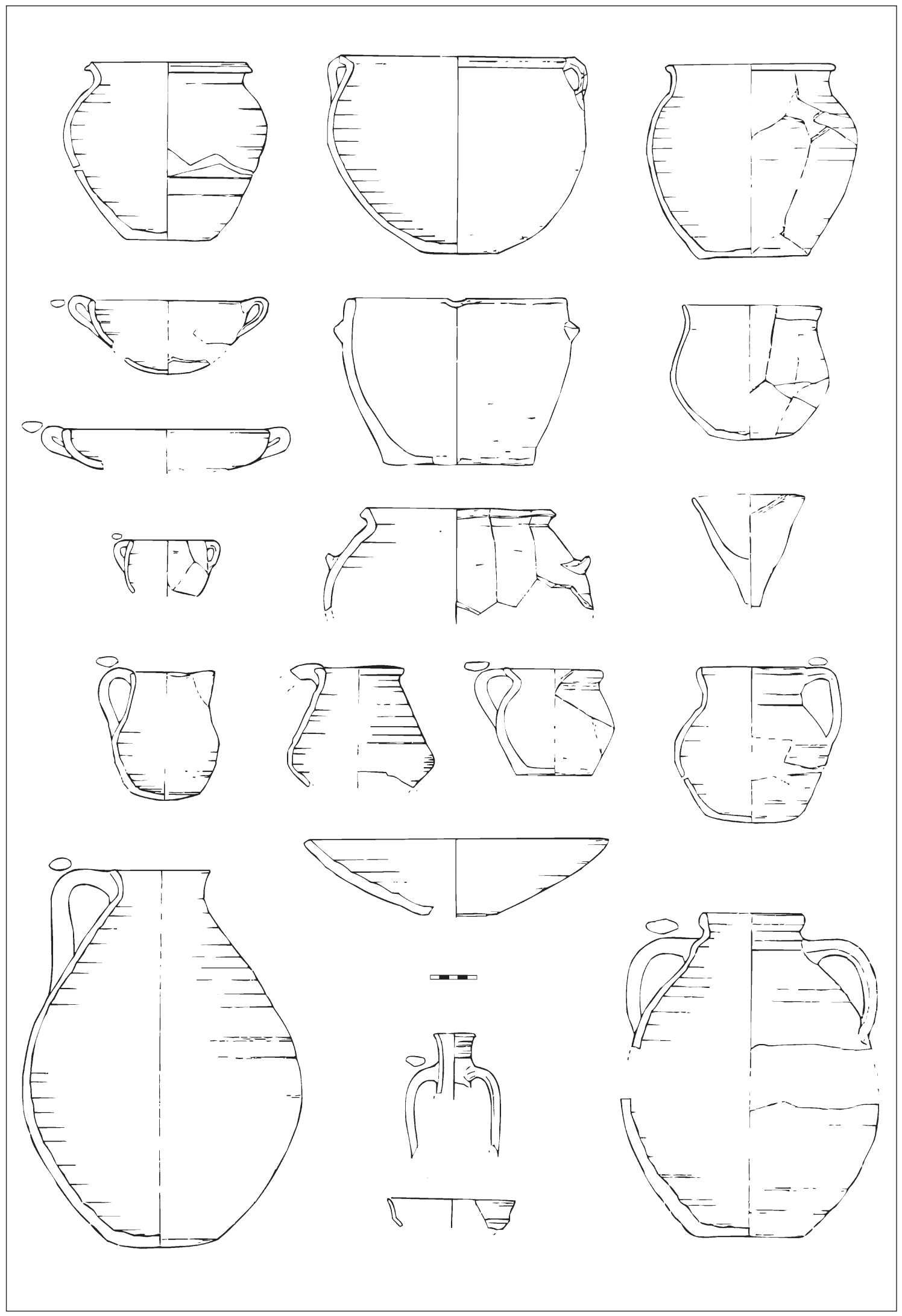

Figura 2. Cuadro de síntesis del horizonte Il a partir de los materiales documentados en la basílica (GUTIÉRREZ, GAMO y AMORÓS, 2003: 159). 


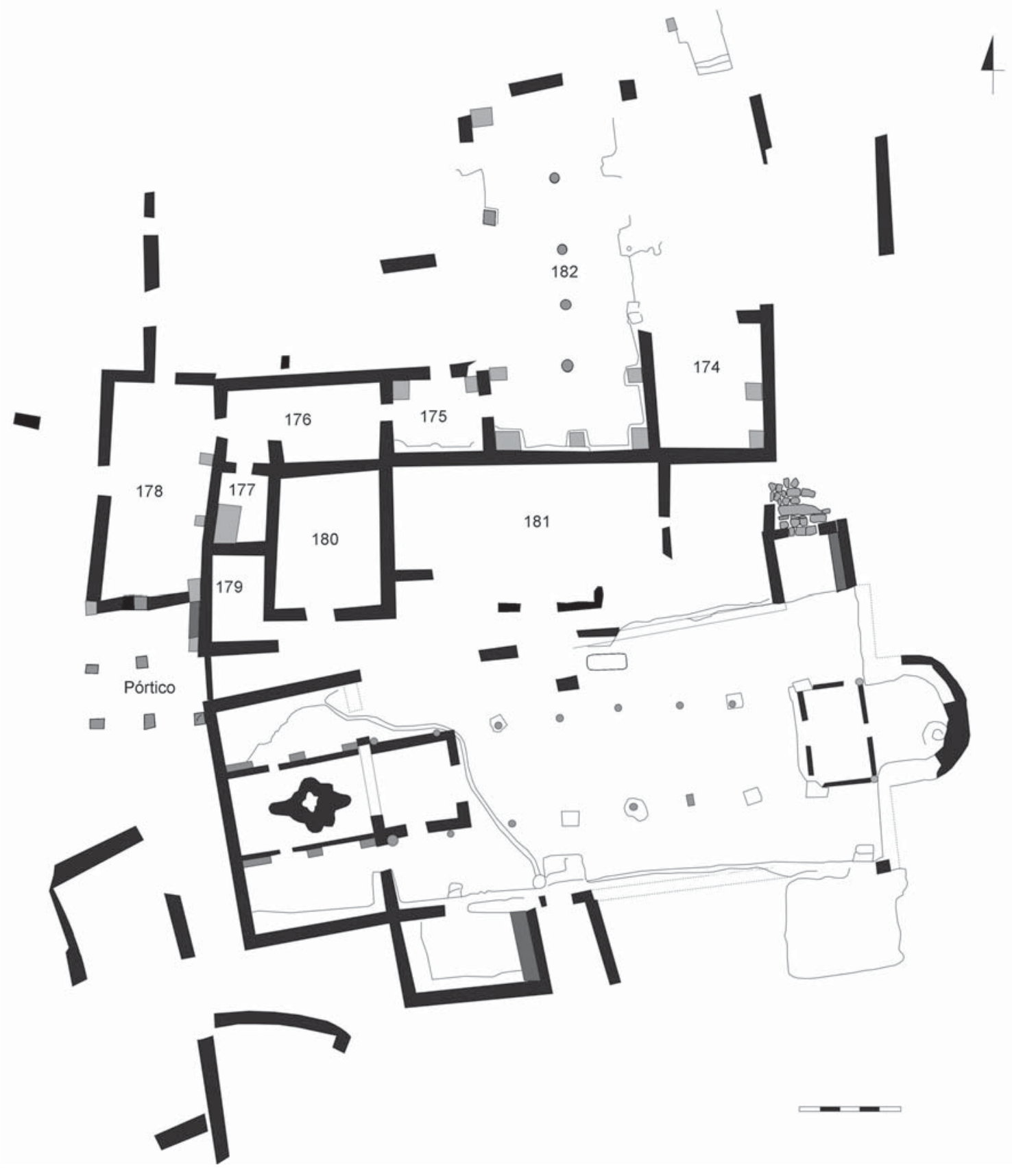

Figura 3. Planta del conjunto monumental visigodo con las estructuras conservadas en macizado. Los números denominan las habitaciones y espacios del palacio reempleados. 

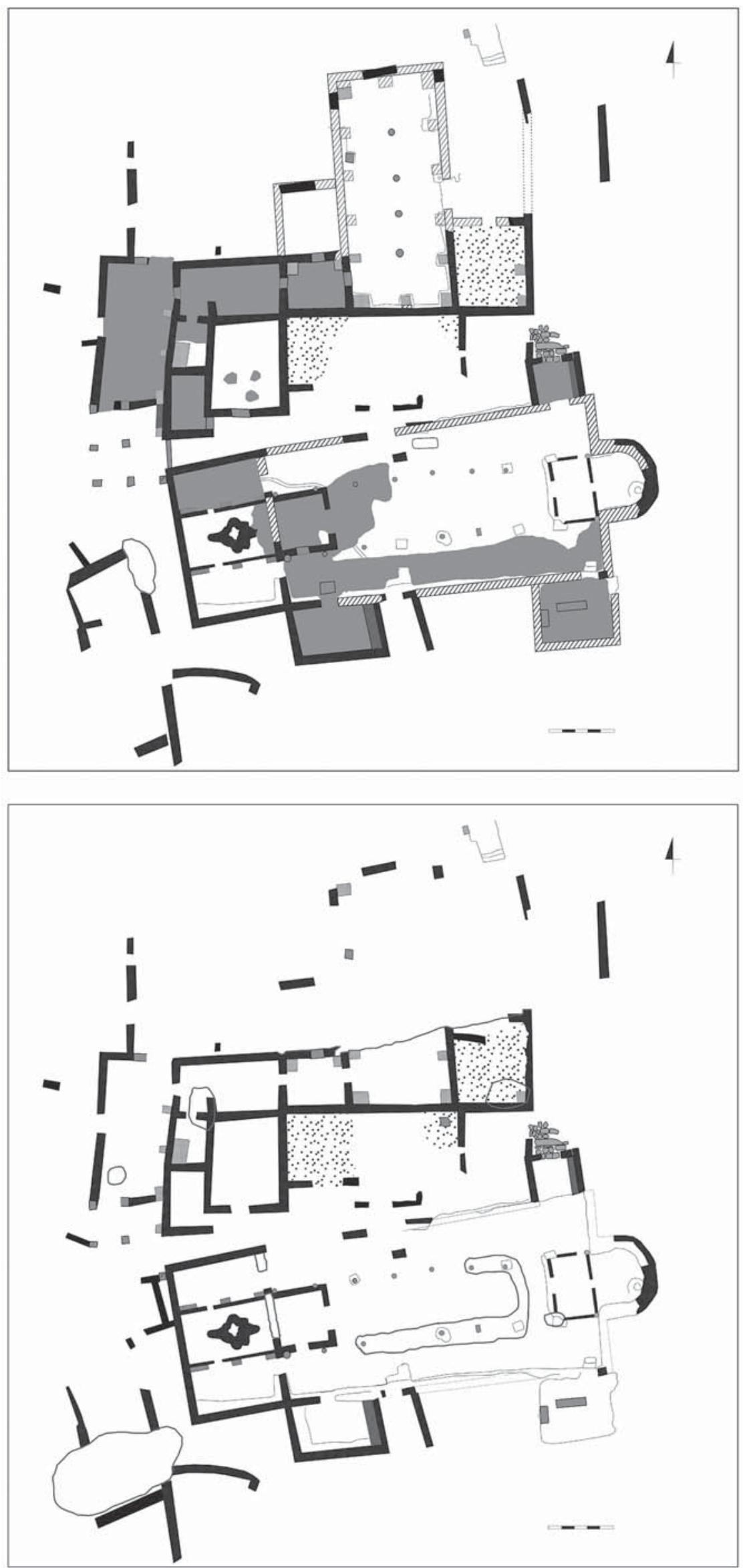

Figura 4. Plantas que marcan los dos momentos de uso del palacio durante el periodo estudiado. En el primero se observan pavimentos de tierra anaranjada correspondientes a la readaptación doméstica del conjunto; así como otros usos asociados a nuevas construcciones. En el segundo, se atestiguan usos y frecuentaciones así como zanjas de expolio. 


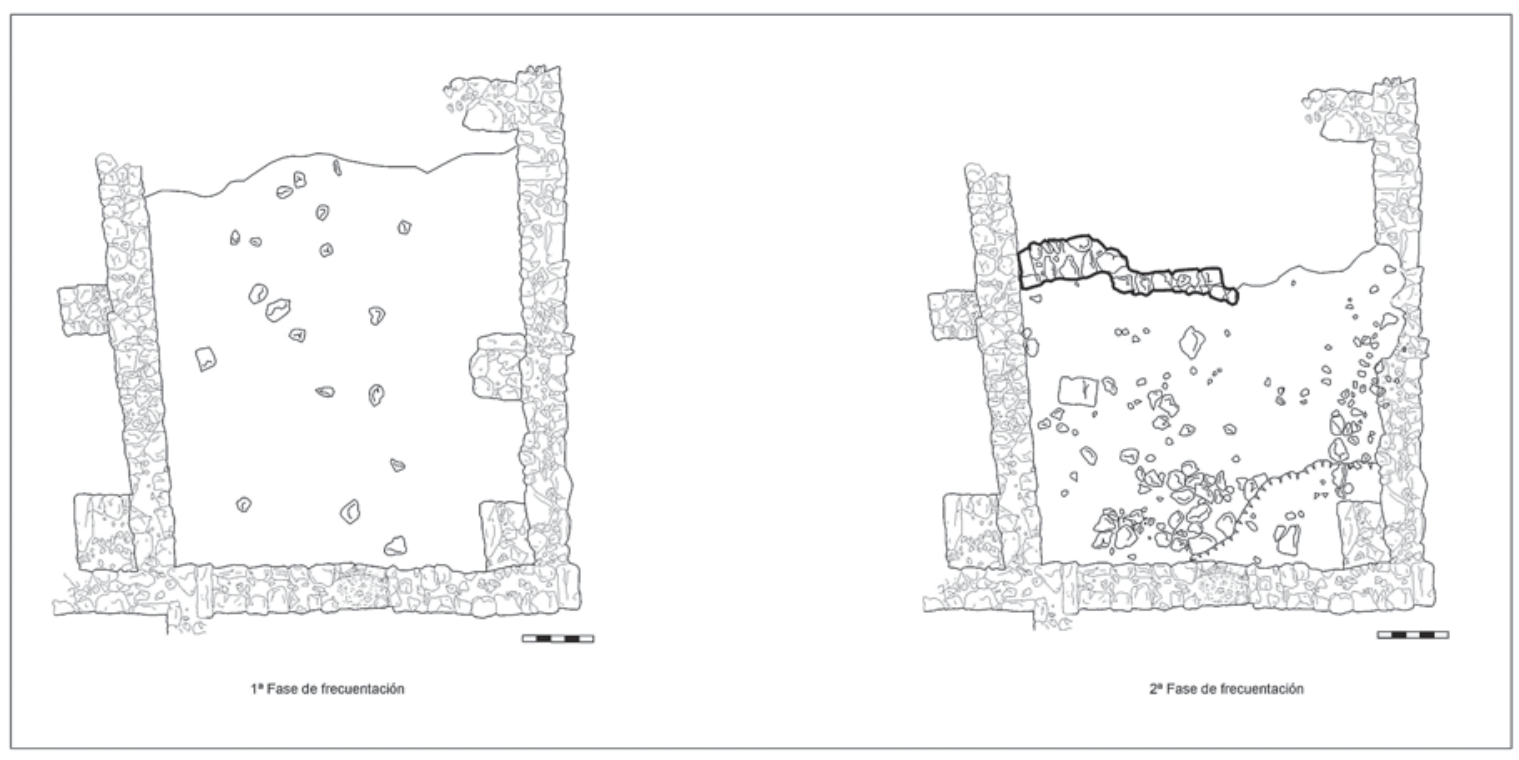

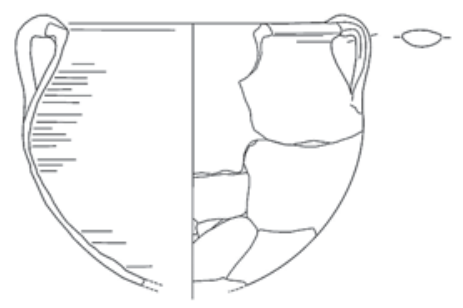

6

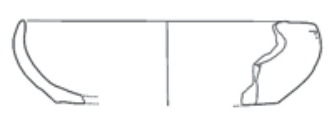

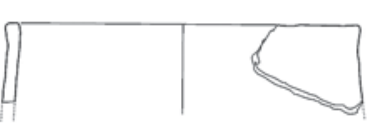

2

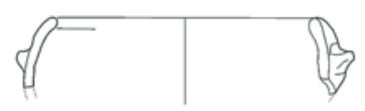

5
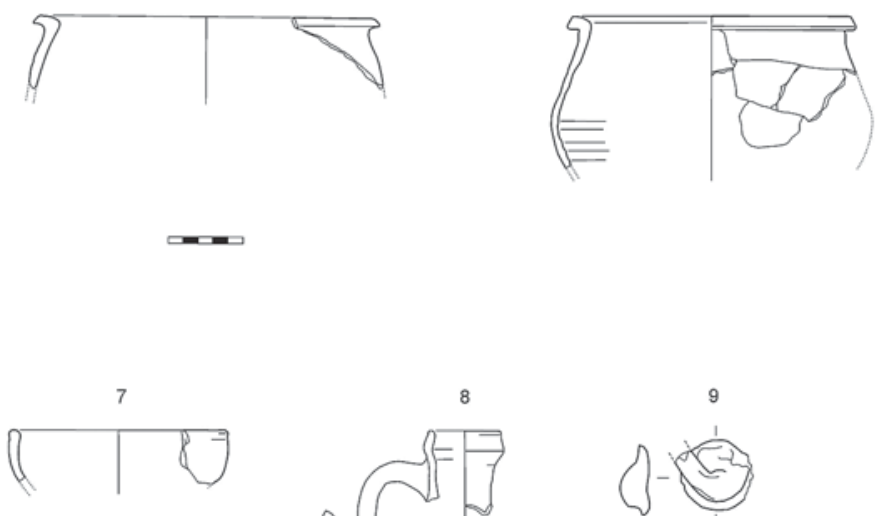

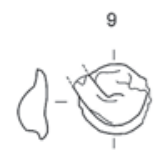

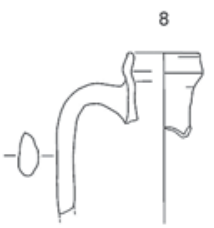

Figura 5. Plantas de los dos niveles de frecuentación documentados en la habitación 1 74, y materiales documentados en los paquetes que amortizan a ambos niveles. 

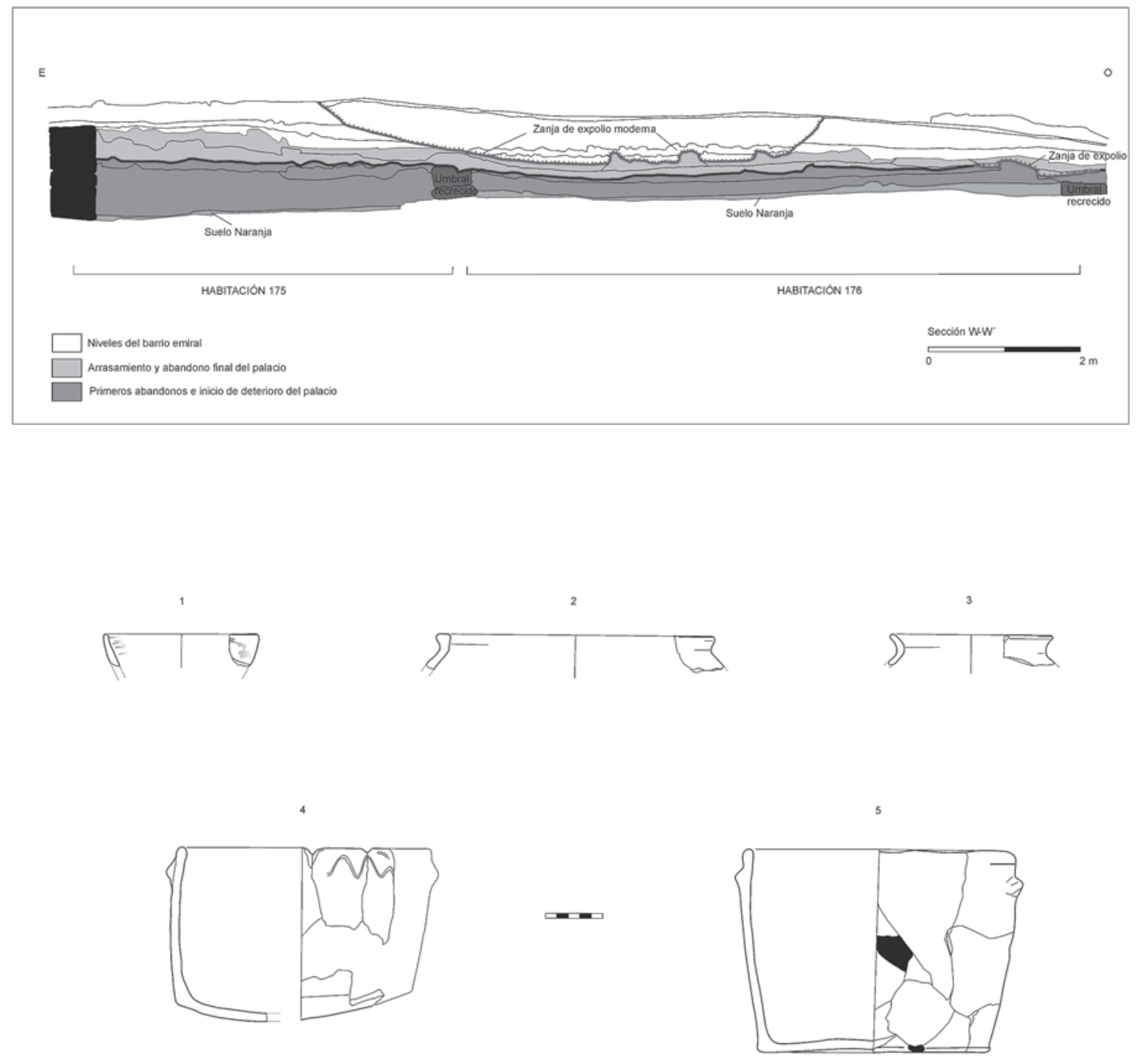

Figura 6. Tramo de la sección Este-Oeste a su paso por las habitaciones 175 y 176, y materiales documentados en ambas. 

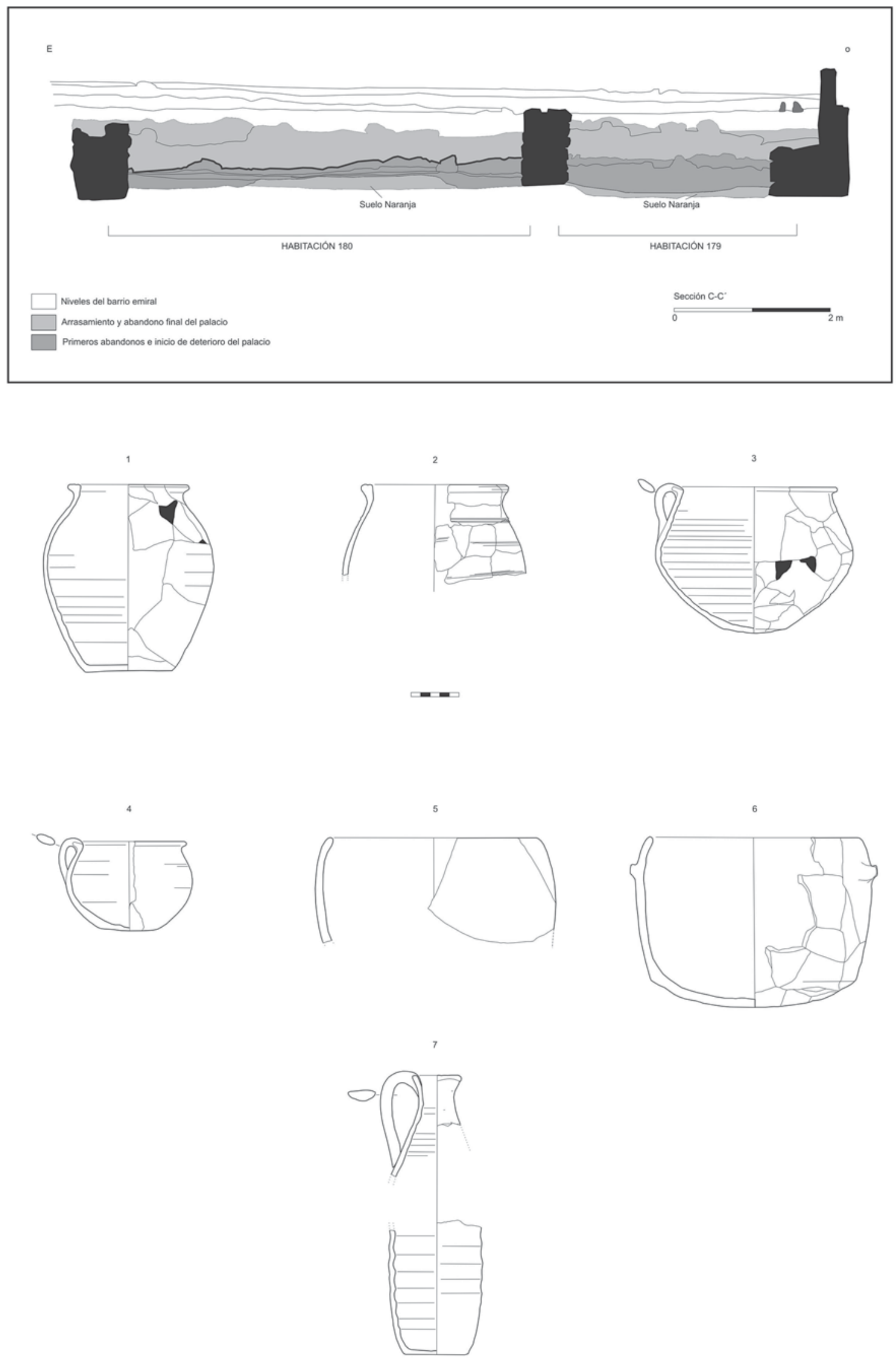

Figura 7. Tramo de la sección Este-Oeste a su paso por las habitaciones 179 y 180, y materiales documentados en ambas. 

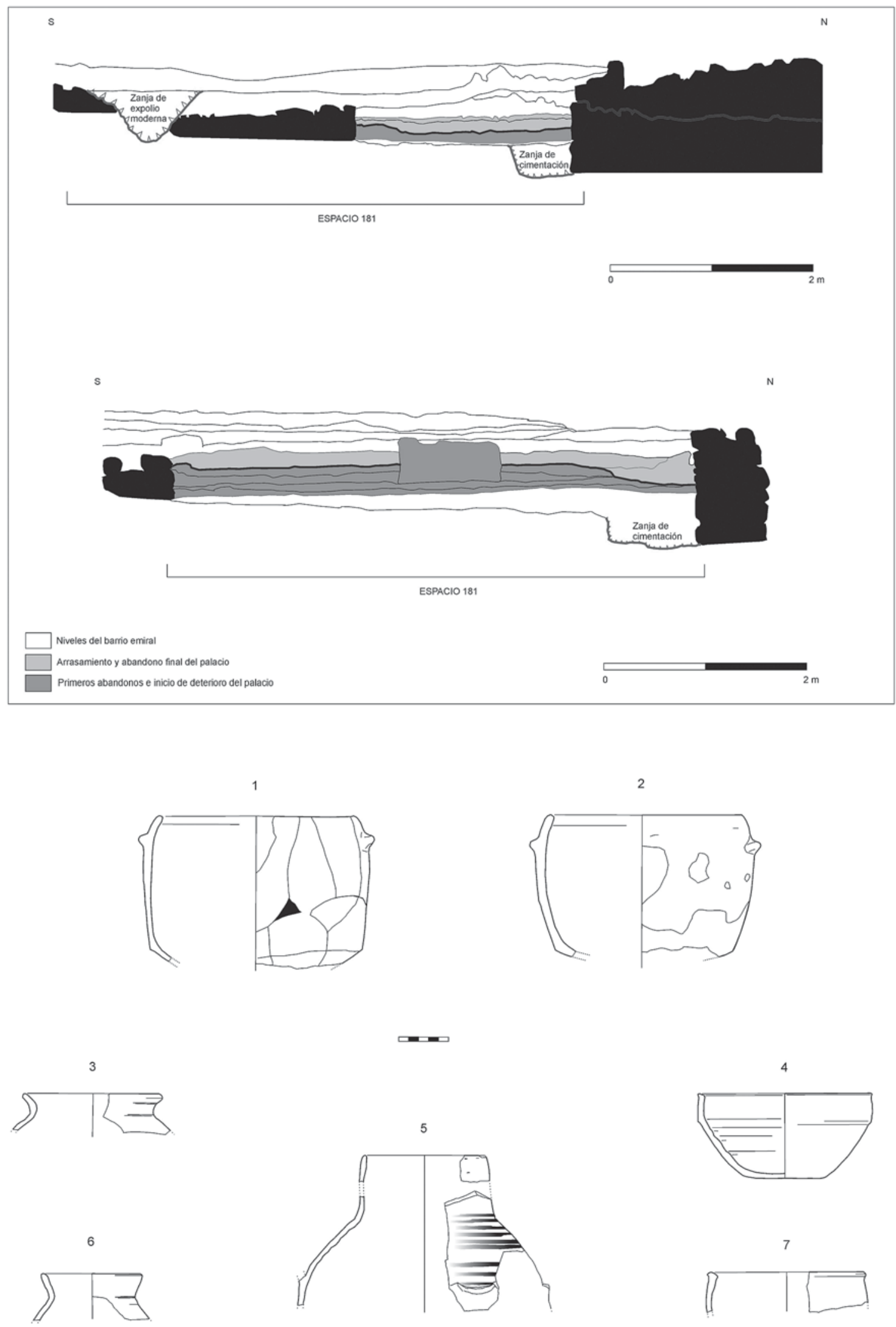

Figura 8. Tramo de dos secciones Norte-Sur a su paso por el espacio I 81, y materiales documentados. 